\title{
Children, comorbidities and COVID-19 - What tilts the balance?
}

\author{
Umesh Shukla', Nita Radhakrishnan², Bhanu Kiran Bhakhri³, Ravi Shankar", \\ Sohini Ghosh ${ }^{5}$, Vikas Jain ${ }^{1}$, Dharmendra K Singh ${ }^{6}$, Devendra K Gupta \\ ${ }^{1}$ Assistant Professor, Department of Pediatric Gastroenterology, Super Speciality Pediatric Hospital and Post Graduate \\ Teaching Institute, Noida, Delhi NCR, India, ${ }^{2}$ Assistant Professor, Department of Pediatric Hematology-Oncology, Super \\ Speciality Pediatric Hospital and Post Graduate Teaching Institute, Noida, Delhi NCR, India, ${ }^{3}$ Associate Professor, ${ }^{5}$ Senior \\ Resident, ${ }^{6}$ Professor, Department of Pediatric Medicine, Super Speciality Pediatric Hospital and Post Graduate Teaching \\ Institute, Noida, Delhi NCR, India, ${ }^{4}$ IAP Fellow, Department of Pediatric Hematology-Oncology, Super Speciality Pediatric \\ Hospital and Post Graduate Teaching Institute, Noida, Delhi NCR, India, ${ }^{7}$ Director, SSPHPGTI and Professor, Department \\ of Pediatric Surgery, Super Speciality Pediatric Hospital and Post Graduate Teaching Institute, Noida, Delhi NCR, India
}

Background: Data on the outcome of children with SARS-COV-2 infection (COVID-19) is still evolving as the pandemic unfolds. Aims and Objective: The present study aims at describing the clinical severity, course and outcome of COVID-19 in children who had underlying illnesses or co-infections. Materials and Methods: Retrospective, single center, observational study, conducted in a pediatric tertiary care center at Noida (National Capital Region, India). Results: We analyzed the data of 15 children with co-morbidities associated with COVID-19. Cancer $(n=4,26.6 \%)$, co-infections $(n=5,33.3 \%)$, Thalassemia major $(n=2,13.3 \%)$ and one child each with celiac disease, cholelithiasis, Duchenne muscular dystrophy and multiple rib fractures were diagnosed with COVID-19. None were asymptomatic. 9 children $(60 \%)$ had mild symptoms and 4 had moderate symptoms $(26.6 \%)$ with respiratory distress. 2 children had severe respiratory distress requiring high flow oxygen. Convalescent plasma, IVIG, Oseltamivir, Azithromycin, Hydroxychloroquine were given as treatment in varying combinations. All children recovered from COVID-19. Conclusion: Active malignancy, hypogammaglobinemia, underlying lung disease were associated with moderate to severe symptoms in this series of patients. Convalescent plasma helped in both children with severe hypoxia.

Key words: COVID-19; Comorbidities; Children; Cancer

\section{Access this article online}

Website:

http://nepjol.info/index.php/AJMS DOI: 10.3126/ajms.v12i3.32738

E-ISSN: 2091-0576

P-ISSN: 2467-9100

Copyright (c) 2021 Asian Journal of Medical Sciences

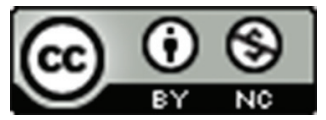

This work is licensed under a Creative Commons Attribution-NonCommercial 4.0 International License.

\section{INTRODUCTION}

As we move through what will perhaps be the largest medical catastrophe in modern times, many questions regarding COVID-19 infection remain unanswered. The course of the illness, factors predicting outcome, relation to age and co-morbidities and the role of various therapies are just a few among them. It has so far been recognized that this infection is less severe in children compared to adults. ${ }^{1}$ As seen in non-COVID-19 infections, it is yet to be defined if younger age, underlying lung pathology and prior immunocompromised states are associated with severe outcome. ${ }^{2}$ As per the Center for Disease Control and Prevention, an increased risk for severe COVID-19 illness is observed in patients with cancer, chronic obstructive pulmonary disease, immunocompromised state from solid organ transplant, obesity, type 2 diabetes, sickle cell disease and heart disease. Although severe and fatal forms of COVID-19 have been encountered in children, there are no studies evaluating risk for the same in pediatric age group. ${ }^{3}$ In the current paper, we analyze the presentation and outcome of children with COVID-19 and co-morbidities.

\section{MATERIALS AND METHODS}

The study is a retrospective analysis of the clinical presentation and outcome of children aged $0-18$ years 
admitted with a diagnosis of COVID-19 with associated co-morbidities that were either diagnosed prior to or along with this infection. Our institute is a tertiary care pediatric government facility that has been catering to COVIDpositive patients from Gautam Budh Nagar (Noida) and neighboring districts in Uttar Pradesh such as Ghaziabad, Bulandshahr, Kasganj, and the neighboring state of New Delhi. Patients diagnosed during a period of 25 weeks from 23 March 2020 to 13 September 2020 were included in this analysis. In addition, few patients who were primarily being followed up at our center for their underlying medical condition (eg. Thalassemia major) and were diagnosed with COVID-19 by district administration during this period were also included in the analysis. Diagnosis of COVID-19 was done in the department of Microbiology of our institute or from other government approved laboratories in this area. For patients admitted to our center, prospectively maintained electronic records were used for demographic profile, contact history, clinical presentation and outcome. For those diagnosed with COVID-19 outside, the details of the infection were collected at the next hospital visit.

\section{RESULTS}

During the study period, 460 patients of all ages were admitted with COVID-19 to our center, of which 118 were children $(25.6 \%) .15$ out of these 118 children $(12 \%)$ had co-morbidities and were included in this study. The median age of this cohort was 8.5 years (Range 2 months to 17 years). There was no sex predilection. The underlying disease included malignancy in $4(26 \%)(2$ acute lymphoblastic leukemia (ALL), 1 chronic myeloid leukemia (CML) and 1 Wilms tumor), pulmonary tuberculosis in $3(20 \%)$, Thalassemia major in $2(13 \%)$ (one patient was HIV positive), and 1 case each of celiac disease, cholelithiasis, Duchenne muscular dystrophy and multiple rib fracture with orbital fractures. 2 children were diagnosed with co-infections; plasmodium falciparum Malaria and Acinetobacter sepsis with meningitis. The clinical severity, treatment given and outcome is given in Table 1.

Three of these children did not have any household contact. In rest the disease was part of a cluster in the family. It is interesting to note that in these children with co-morbidities, majority of patients were symptomatic. 2 children (13\%) had severe and 4 children $(26 \%)$ had moderate respiratory distress. All presented with only respiratory complaints. 2 children had anosmia. None had gastrointestinal or neurological features of the infection. 2 children were noted to have maculopapular rash (Figure 1).
On evaluation of the underlying cause and clinical severity, underlying hematological malignancy and lung involvement (both pulmonary tuberculosis or hydro-pneumothorax following rib fracture) emerged as predictive of moderate to severe COVID-19 illness. Both children with leukemia presented with COVID pneumonia with respiratory distress (Figure 2); one was a 15-year-old girl who presented with COVID at initial diagnosis of leukemia where she presented with distressing cough, hypoxia and pancytopenia which on evaluation was proven to be due to $\mathrm{B}$ precursor acute lymphoblastic leukemia (B-ALL). The other 4-yearold girl also had B-ALL in remission (minimal residual disease $0 \%$ ) and was on interim maintenance therapy with daily 6-Mercaptopurine and weekly methotrexate. She presented with fever and neutropenia followed by breathlessness on Day 5. She had low IgG $(<400 \mathrm{mg} / \mathrm{dl}$ ) at admission. Both patients had hypoxia requiring oxygen support including high flow nasal oxygen support for 7-10 days. A second spike of fever in week 2 of the illness with rash was noted in the older patient with leukemia which subsided following introduction of prednisolone. In the child with Wilms tumour, low grade fever was followed by rash on day 2 of illness. He remained asymptomatic henceforth.

Both children with severe respiratory distress were managed with dexamethasone, convalescent plasma ( 2 doses in Patient 10 and 1 dose in Patient $15 @ 15 \mathrm{ml} / \mathrm{kg} /$ dose),

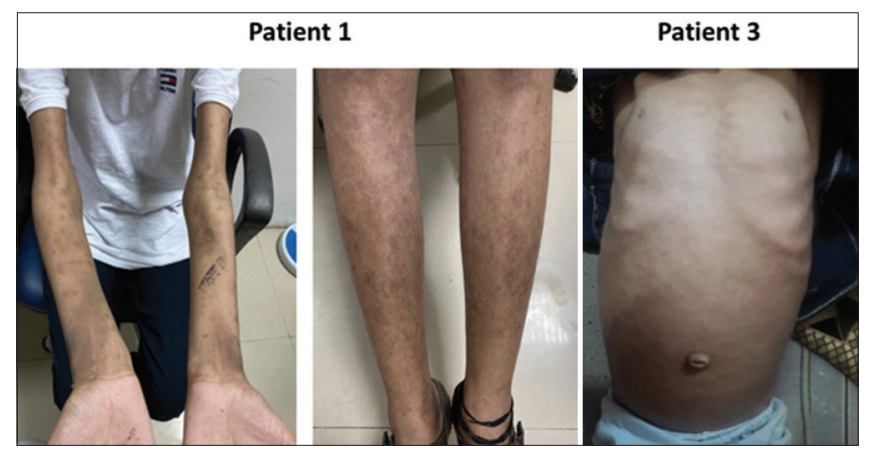

Figure 1: Maculopapular Rash in children with COVID-19

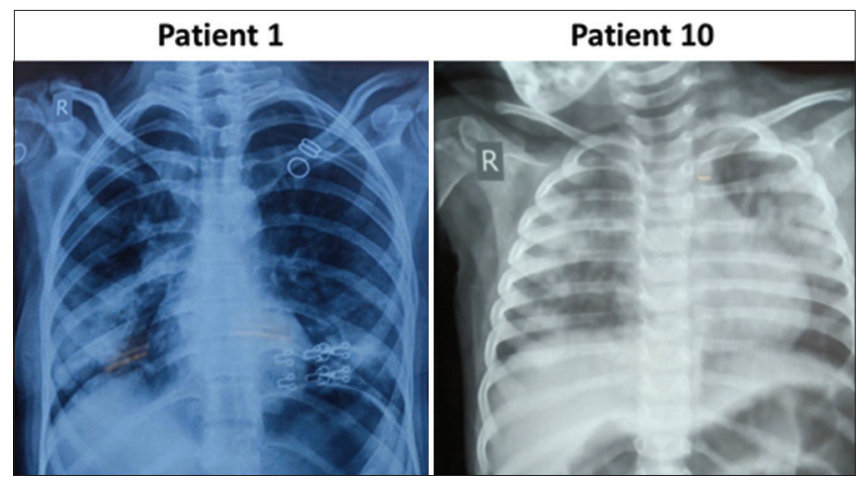

Figure 2: Chest X Ray in children with cancer and COVID-19 pneumonia 


\begin{tabular}{|c|c|c|c|c|c|c|c|}
\hline SI. NO. & $\begin{array}{c}\text { Age } \\
\text { (years) }\end{array}$ & Sex & Underlying condition & $\begin{array}{l}\text { COVID-19 } \\
\text { severity }\end{array}$ & $\begin{array}{c}\text { Lowest } \mathrm{O}_{2} \text { saturation } \\
\text { (room air) }\end{array}$ & Treatment & Outcome \\
\hline Patient 1 & 15 & $\mathrm{~F}$ & $\begin{array}{l}\text { Acute Lymphoblastic } \\
\text { Leukemia }\end{array}$ & Moderate & $85 \%$ & $\begin{array}{l}\text { Azithromycin, HCQS, } \\
\text { Oseltamivir, Steroids }\end{array}$ & Recovered \\
\hline Patient 2 & 9 & M & Celiac disease & Mild & $96 \%$ & Symptomatic treatment & Recovered \\
\hline Patient 3 & 3 & M & Wilms tumor & Mild & $97 \%$ & Symptomatic treatment & Recovered \\
\hline Patient 4 & 10 & M & $\begin{array}{l}\text { Duchenne muscular } \\
\text { dystrophy }\end{array}$ & Mild & $99 \%$ & Symptomatic treatment & Recovered \\
\hline Patient 5 & 17 & $\mathrm{~F}$ & Pulmonary Tuberculosis & Moderate & $97 \%$ & $\begin{array}{l}\text { Symptomatic } \\
\text { treatment, ATT, } \\
\text { HCQS, Antibiotics, } \\
\text { Azithromycin }\end{array}$ & Recovered \\
\hline Patient 6 & 11 & M & Chronic Myeloid Leukemia & Mild & $98 \%$ & No specific treatment & Recovered \\
\hline Patient 7 & 4 & $\mathrm{~F}$ & Thalassemia Major & Mild & $99 \%$ & No specific treatment & Recovered \\
\hline Patient 8 & 1.5 & $\mathrm{~F}$ & $\begin{array}{l}\text { Left hydro pneumothorax } \\
\text { Rib and orbital fracture }\end{array}$ & Moderate & $97 \%$ & $\begin{array}{l}\text { Symptomatic } \\
\text { treatment, Antibiotics }\end{array}$ & Recovered \\
\hline Patient 9 & 11 & $\mathrm{~F}$ & Cholelithiasis & Mild & $98 \%$ & Symptomatic treatment & Recovered \\
\hline Patient 10 & 4 & $\mathrm{~F}$ & $\begin{array}{l}\text { Acute Lymphoblastic } \\
\text { Leukemia }\end{array}$ & Severe & $55 \%$ & $\begin{array}{l}\text { Azithromycin, HCQS, } \\
\text { Convalescent plasma, } \\
\text { Oseltamivir, Steroids }\end{array}$ & Recovered \\
\hline Patient 11 & 17 & M & $\begin{array}{l}\text { Thalassemia Major (HIV } \\
\text { positive) }\end{array}$ & Mild & $99 \%$ & $\begin{array}{l}\text { Symptomatic } \\
\text { treatment, ART }\end{array}$ & Recovered \\
\hline Patient 12 & 14 & M & Pulmonary Tuberculosis & Moderate & $90 \%$ & $\begin{array}{l}\text { Symptomatic } \\
\text { treatment, ATT }\end{array}$ & Recovered \\
\hline Patient 13 & 2.5 & M & Pulmonary Tuberculosis & Mild & $95 \%$ & $\begin{array}{l}\text { Symptomatic } \\
\text { treatment, ATT }\end{array}$ & Recovered \\
\hline Patient 14 & 8 & $\mathrm{~F}$ & Malaria & Mild & $98 \%$ & $\begin{array}{l}\text { Symptomatic } \\
\text { treatment, } \\
\text { Antimalarials }\end{array}$ & Recovered \\
\hline Patient 15 & 0.16 & $\mathrm{~F}$ & $\begin{array}{l}\text { Acinetobacter Sepsis and } \\
\text { Meningitis }\end{array}$ & Severe & $90 \%$ & $\begin{array}{l}\text { Antibiotics, } \\
\text { Convalescent plasma, } \\
\text { Azithromycin }\end{array}$ & Recovered \\
\hline
\end{tabular}

azithromycin and oseltamivir. The 4-year-old girl with ALL received Intravenous immunoglobulin (IVIG) @1 gram $/ \mathrm{kg}$. Children $>12$ years of age received Hydroxychloroquine. Symptomatic treatment was given to the rest. 4 children (2 thalassemia, 1 Wilms tumour and $1 \mathrm{CML}$ ) were mild/ asymptomatic and advised home quarantine. D-Dimer, Ferritin, C-reactive protein (CRP) and Procalcitonin were monitored in all symptomatic children since 5 July 2020. Raised D Dimer was observed in patients 10 and $15(3500 \mathrm{ng} / \mathrm{ml}$ and $5839 \mathrm{ng} / \mathrm{ml}$ respectively). None required Tocilizumab, Remdesivir or other antivirals. Absent serological response to SARS-COV-2 (Negative IgM to SARS-COV-2 on Days 4 and 5 of illness) was demonstrated in both these children with severe disease prior to convalescent plasma transfusion.

\section{DISCUSSION}

COVID-19 outbreak has a much milder presentation in children compared to adults. This has been postulated to be due to differences in immune response, lower expression of Acetyl Choline Esterase-2 receptors and lesser comorbidities in children. Children with their distinct immune system have been known to handle infections differently compared to adults. ${ }^{4}$ Although our study population is heterogeneous, we attempt to analyze the factors that could have caused clinical severity. Similar to other pediatric series on COVID, all ages and both sexes were equally affected. ${ }^{5,6}$ Majority of our patients had a household contact as part of a cluster attack. Majority of these patients were symptomatic, unlike in pediatric COVID series where asymptomatic patients range from $20-30 \%$.

The differences in clinical presentation among these children with co- illnesses, demonstrate the role of host response in handling this infection. Also, to note is the fact that in 3 of the most severely affected children, the caretaker was negative for virus and no contact was traceable. Since they were essentially homebound for 2-3 weeks prior to this illness, the infection had to come from other household contacts that probably were asymptomatic. Among compartments of immune system that mount the host's response to COVID-19, both innate and adaptive compartments have been demonstrated to have a role. ${ }^{7}$ Viruses are able to circumvent the immune attack in many individuals thus resulting in disseminated infection with severe inflammatory response. The knowledge of the immune response is helpful in facilitating development of approaches to prevent and treat the disease. ${ }^{7}$ 
A hypothesis of dysregulated immune system in elderly as a cause of disease worsening by the end of first week of illness has been postulated. ${ }^{8}$ In our series, children with acute leukemia presented with moderate-severe illness whereas children with CML in remission on Imatinib mesylate (targeted therapy) and Wilms tumor had a mild course. The capability to mount an effective immune response could be inferred to be low in both these children with acute lymphoblastic leukemia either as a result of active disease or hypogammaglobinemia secondary to lymphopenic chemotherapy. Poor adaptive immune response to mount anti-viral immunity could be the reason for the clinical presentation in both these cases. This is why other children at-risk children with solid tumor, chronic myeloid leukemia on targeted therapy (without chemotherapy) and HIV positive thalassemia patient on antiretroviral therapy had a mild course as their adaptive immune response is expected to be near normal. Although the typical cytokine storm was not noted in any child, patient 1 with ALL presented with a second spike on fever in the second week of illness with diffuse maculopapular rash, which improved following introduction of prednisolone.

All 3 children with pulmonary tuberculosis and one child with hydro-pneumothorax following traumatic rib fracture had moderate illness. Prior lung pathology thus was noted to be linked to severity.

Compared to other co-morbidities, immunosuppression was noted to have a favourable outcome as per a systematic review conducted among studies conducted mainly in China early in the outbreak. ${ }^{9}$ However unlike in their data, we have fortunately not observed any mortality in these children, probably because of the "collective wisdom" of those before us in this battle from countries such as China, Italy and the United States. Our share of sick and critically ill children with comorbidities responded to early steroids (dexamethasone in 3, prednisolone in 1), IVIG $(\mathrm{n}=1)$ and convalescent plasma $(n=2)$ or a combination.

\section{CONCLUSION}

Although COVID-19 outbreak has been described to be milder in children, there are subsets of children with co-morbidities who can present with moderate to severe disease. What tips the balance towards severe disease in children with co-morbidities were cancers with poor adaptive immune response and underlying lung disease. Early use of steroids and convalescent plasma helps in recovery.

\section{REFERENCES}

1. Cruz AT and Zeichner SL. COVID-19 in Children: Initial Characterization of the Pediatric Disease. Pediatrics. 2020;145(6):e20200834.

https://doi.org/10.1542/peds.2020-0834

2. Ogimi C, Englund JA, Bradford MC, Qin X, Boeckh M and Waghmare A. Characteristics and Outcomes of Coronavirus Infection in Children: The Role of Viral Factors and an Immunocompromised State. J Pediatric Infect Dis Soc. 2019;8(1):21-28

https://doi.org/10.1093/jpids/pix093

3. Oualha $M$, Bendavid $M$, Berteloot L, Corsia A, Lesage $F$, Vedrenne F, et al. Severe and fatal forms of COVID-19 in children. Arch Pediatr. 2020; 27(5):235-238.

https://doi.org/10.1016/j.arcped.2020.05.010

4. Sun D, Li H, Lu XX, Xiao H, Ren J, Zhang FR, et al. Clinical features of severe pediatric patients with coronavirus disease 2019 in Wuhan: a single center's observational study. World J Pediatr. 2020; 16(3):251-259. https://doi.org/10.1007/s12519-020-00354-4

5. Dong $\mathrm{Y}, \mathrm{Mo} X, \mathrm{Hu} \mathrm{Y}, \mathrm{Qi} X$, Jiang F, Jiang $Z$ and Tong S. Epidemiology of COVID-19 Among Children in China. Pediatrics. 2020;145(6):e20200702.

https://doi.org/10.1542/peds.2020-0702

6. Zhang L, Peres TG, Silva MVF and Camargos P. What we know so far about Coronavirus Disease 2019 in children: A metaanalysis of 551 laboratory-confirmed cases. Pediatr Pulmonol. 2020; 55(8):2115-2127.

https://doi.org/10.1002/ppul.24869

7. Chang FY, Chen HC, Chen PJ, Ho MS, Hsieh SL, Lin JC, et al. Immunologic aspects of characteristics, diagnosis, and treatment of coronavirus disease 2019 (COVID-19). J Biomed Sci. 2020; 27(1):72.

https://doi.org/10.1186/s12929-020-00663-w

8. Rao VUS, Arakeri G, Subash A, Rao J, Jadhav S, Suhail Sayeed M, et al. COVID-19: Loss of bridging between innate and adaptive immunity? Med Hypotheses. 2020; 144:109861. https://doi.org/10.1016/j.mehy.2020.109861

9. Minotti C, Tirelli F, Barbieri E, Giaquinto $C$ and Donà D. How is immunosuppressive status affecting children and adults in SARS-CoV-2 infection? A systematic review. J Infect. 2020; 81(1):e61-e66.

https://doi.org/10.1016/j.jinf.2020.04.026

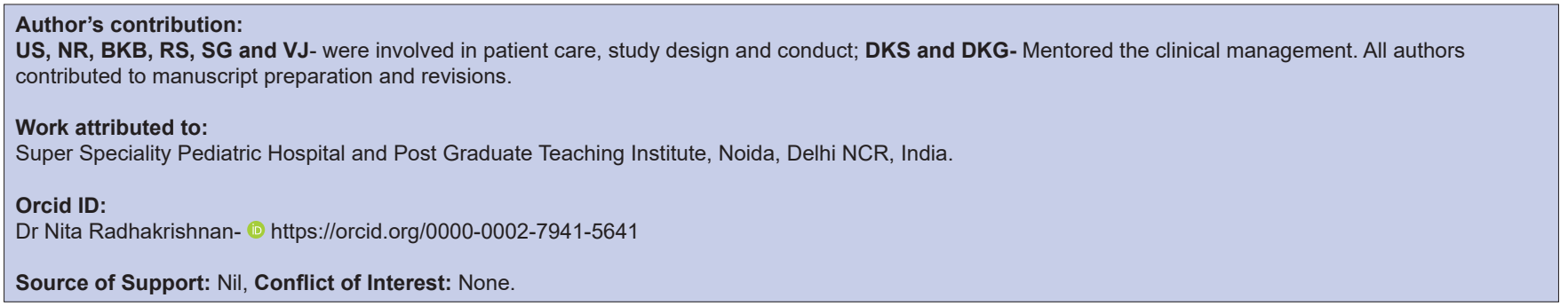

